\title{
DI-3-n-Butylphthalide promotes neovascularization and neurological recovery in a rat model of intracerebral hemorrhage
}

\author{
Ewen Tu ${ }^{1 *} \mathbb{D}$, Qiong Chen ${ }^{2}$, Li Tan ${ }^{1}$ and Yan Wang ${ }^{1}$
}

\begin{abstract}
Background: Cerebral stroke occurs following ischemic and hemorrhagic lesions in the brain. Survival and recovery of stroke patients depend on the severity of the initial injury but also the therapeutic approaches applied for emergent lifesaving and continuing post-stroke management. DI-3-n-Butylphthalide (NBP), an active compound derived from Chinese celery seeds, has shown clinical efficacy in the treatment of ischemic cerebral stroke.

Results: In the present study we explored the therapeutic effect of NBP in a rat model of intracerebral hemorrhage $(\mathrm{ICH})$, focusing on its potential role in promoting neovascularization in the perihemorrhagic zone. ICH was induced in male Sprague-Dawley rats by unilateral injection of autologous blood into the globus pallidus, with sham-operated (Sham group), vehicle-treated (ICH) and NBP-treated (at 10 and $25 \mathrm{mg} / \mathrm{kg} / \mathrm{Bid}$, p.o., ICH + NBP10 and ICH + NBP25, respectively) groups examined behaviorally, macroscopically, histologically and biochemically at 1, 3, 7 and 15 days (d) post operation. Rats in the ICH + NBP10 and ICH + NBP25 groups showed reduced Longa's motor scores relative to the $\mathrm{ICH}$ groups at the 3 and $7 \mathrm{~d}$ time points, while the hematoma volume was comparable in the two NBP relative to the ICH groups as measured at $7 \mathrm{~d}$ and $15 \mathrm{~d}$. In the perihemorrhagic zone, the numeric density of blood vessels immunolabeled by CD34, an angiogenic marker, was greater in the ICH + NBP10 and ICH + NBP25 than ICH groups, more so in the higher dosage group, at 1,3,7 and 15d. Levels of the vascular endothelial growth factor (VEGF) and angiopoietins-2 (Ang-2) proteins were elevated in the NBP groups relative to the sham and vehicle controls in immunoblotting of tissue lysates from the injection region.
\end{abstract}

Conclusion: These results suggest that NBP can alleviate neurological defects following experimentally induced local brain hemorrhage, which is associated with a potential role of this drug in promoting neovascularization surrounding the bleeding loci.

Keywords: Angiogenesis, Neurorehabilitation, Neurovascular unit, Phytotherapy, Stroke

\section{Background}

Intracerebral hemorrhage (ICH) refers to primary nontraumatic parenchymal bleeding that often onsets suddenly and manifests as acute loss of broad neurological and cognitive functions. All over the world, ICH remains

\footnotetext{
${ }^{*}$ Correspondence: tuewen612@163.com

1 Department of Neurology, Hunan Brain Hospital, Hunan University

of Chinese Medicine, Changsha 410208, Hunan, China

Full list of author information is available at the end of the article
}

associated with high morbidity and mortality, and represents one of the greatest healthcare crises affecting the quality of people's life [1-5]. ICH is the common (consisting of $10-15 \%$ of all stroke cases) but most severe subtype of cerebral stroke, which also includes the cases suffered from ischemic and other insults [6-9]. Much progress has been made in recent years in understanding the pathogenesis of $\mathrm{ICH}[7,10]$. However, unfortunately, none of the current clinical interventions, including aggressive blood pressure control, homeostasis 
management and platelet transfusion, have significantly improved the outcome of cerebral stroke among patients [11-16].

Besides a space-occupying effect, the hematoma formed during $\mathrm{ICH}$ appears to rapidly impair regional blood flow, and thus causing an ischemic effect to the brain tissue adjacent to the bleeding site [17]. The damage in the above so-called perihemorrhagic zone (PHZ) can aggravate neuronal damage and neurological deficits. According to the concept of neurovascular unit (NVU) treatment in management of cerebral stroke, measures to promote angiogenesis are recommended to apply as early as possible when a stroke patient receives medical attention [18-22]. It is considered that, by stimulating angiogenesis in the tissue adjacent to the hematoma, microvascular perfusion and oxygen supply would be improved locally, while the blood-brain barrier is stabilized. A better functioning microcirculation may play a crucial neuroprotective role, thereby improve the neurological recovery [23-27].

The practice of traditional Chinese medicine in the care of patients in China has improved the identification and development of many natural or herbal medicines in clinical management of stroke [28-31]. Among many, an active component of Chinese celery seeds, chemically identified as Dl-3-n-Butylphthalide (NBP), has been recently shown as a promising neuroprotective medicine for the treatment of cerebral stroke and other neurological diseases [32-35]. This compound has been approved by the China Food and Drug Administration for prescription to patients with ischemic brain stroke since 2002 [36]. Its neuroprotective effects against ischemic cerebral stroke have also been investigated in many animal studies, which appear to be related to multiple cellular and molecular mechanisms [37-45], including a potential proangiogenic efficacy $[40,46]$. However, less is known about the therapeutic potential of this compound in experimental models of hemorrhagic cerebral stroke. In the present study, we set out to explore whether NBP administration could alleviate neurological deficits in a rat model of $\mathrm{ICH}$ induced experimentally via intrastriatal blood injection. Given the importance of microvascular functioning in neurological recovery, particular efforts were taken to determine if this compound might promote neovascularization around the hemorrhagic site.

\section{Results}

NBP treatment alleviated neurological deficits in rats with ICH

As reflected by the Longa's scores, the animal groups subjected to induced ICH showed severe neurological deficits relative to the Sham groups at all surviving time points, with a trend of mitigation in movement inability with the increase of surviving time (Fig. 1).

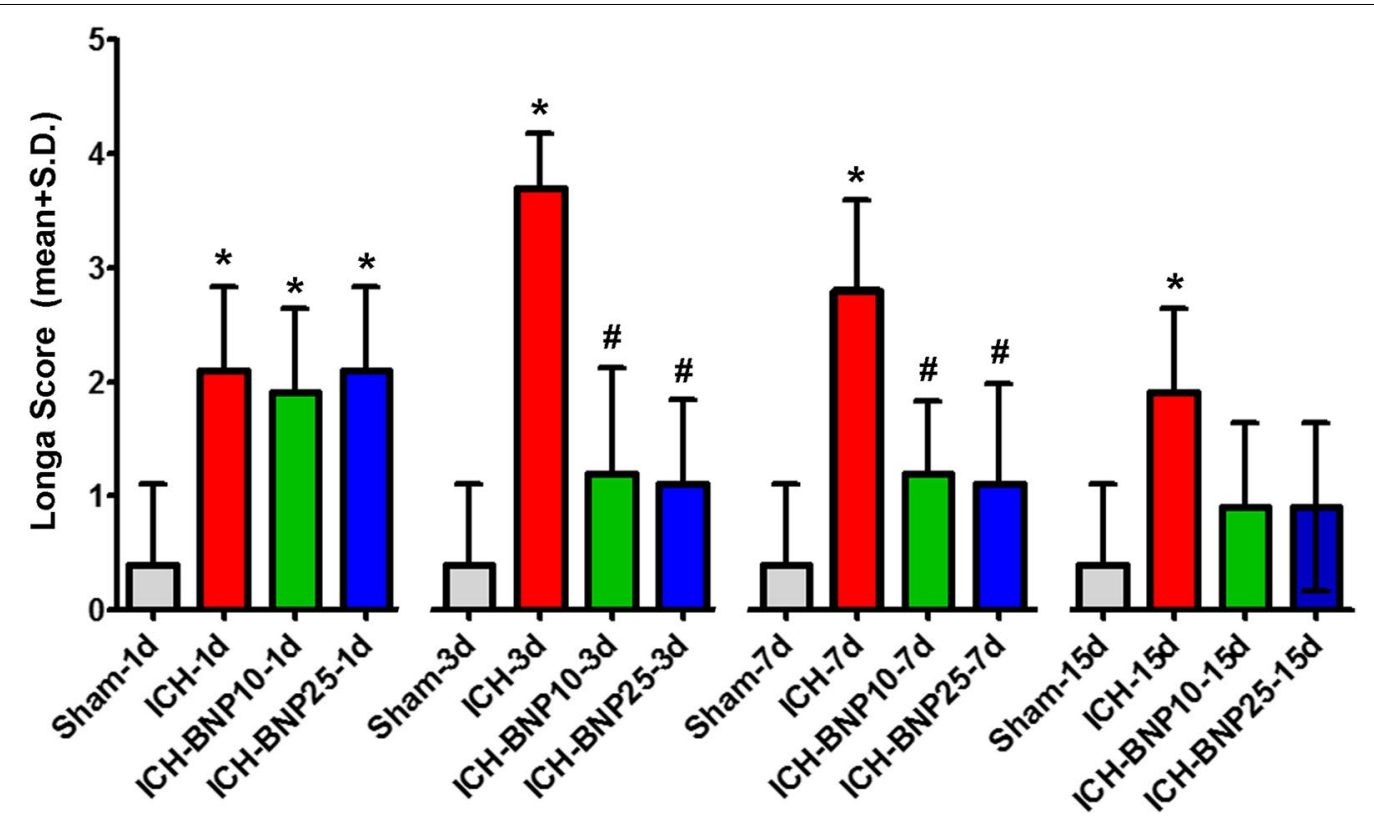

Fig. 1 Effect of NBP treatment on neurological performance in a rat model of experimental intracerebral hemorrhage (ICH). Neurological deficit scores are assessed according to the Langa's scoring method. Scores (mean \pm S.D.) recorded at 1, 3, 7 and 15 days (d) post operation are plotted for the sham-operated groups (Sham), ICH model groups treated with vehicle (ICH), and ICH groups treated with NBP at 10 (ICH+ NBP10) and $25(\mathrm{ICH}+\mathrm{NBP} 25) \mathrm{mg} / \mathrm{kg}$ Bid. Means are analyzed statistically using ANOVA followed by Bonferroni's Multiple Comparison Test as post hoc, with *indicating significantly different in comparison to the Sham groups, and \# indicating significantly different in comparison to the ICH groups 
The worst performance in the ICH groups occurred at the 3rd day post operation. The peak of neurological deficiency in the $\mathrm{ICH}+\mathrm{NBP} 10$ and the $\mathrm{ICH}+\mathrm{NBP} 25$ groups occurred otherwise at the 1st day post operation. Statistically, the neurobehavioral deficit scores were significantly increased in the $\mathrm{ICH}$ groups in comparison with the Sham controls $(\mathrm{P}<0.05$ between all comparing pairs, ANOVA with Bonferroni's post hoc test). In both the $\mathrm{ICH}+\mathrm{NBP} 10$ and $\mathrm{ICH}+\mathrm{NBP} 25$ groups, the deficits were significantly reduced relative to the $\mathrm{ICH}$ (vehicle control) groups at the $3 \mathrm{~d}$ and $7 \mathrm{~d}$ time points. However, in the $15 \mathrm{~d}$ groups, no significant difference remained between the ICH and drug-treated groups, likely owing to the spontaneous recovery of motor functions following the lesion.

\section{NBP treatment did not reduce hematoma size in rats with ICH}

Brains from animals surviving $7 \mathrm{~d}$ and $15 \mathrm{~d}$ post operation were used to measure the hematoma volumes in consecutive coronal slices. On visual inspection, no apparent blood infiltration was seen in the slices from the Sham-operated brains at both time points (Fig. 2a). In contrast, a clear bleeding area was seen around the striatum in the brains from animals subjected to unilateral blood injection (Fig. 2b-d).

Quantitatively, the hematoma volumes were $32.57 \pm 0.31 \mathrm{~mm}^{3}$ and $28.99 \pm 0.12 \mathrm{~mm}^{3}$ in the ICH groups at $7 \mathrm{~d}$ and $15 \mathrm{~d}$ post operation $(\mathrm{n}=5 /$ group/time point), respectively. The values were $32.32 \pm 0.72 \mathrm{~mm}^{3}$ and $28.80 \pm 0.38 \mathrm{~mm}^{3}$ in $\mathrm{ICH}+\mathrm{NBP} 10$ groups, and $32.29 \pm 0.06 \mathrm{~mm}^{3}$ and $28.81 \pm 0.41 \mathrm{~mm}^{3}$ in the $\mathrm{ICH}+\mathrm{NBP} 25$ groups, respectively at the above two time points. Two-way ANOVA analysis showed significant effects related to treatment $(\mathrm{P}<0.0001, \mathrm{Df}=3, \mathrm{~F}=18070)$ and time point $(\mathrm{P}<0.0001, \mathrm{Df}=3, \mathrm{~F}=8095)$ variations. Bonferroni's post hoc tests indicated the differences arose from other groups in comparison with the Sham groups (all $\mathrm{P}<0.001$ ). Thus, no statistically significant differences existed between each pairing set of the means of the $\mathrm{ICH}$, $\mathrm{ICH}+\mathrm{NBP} 10 \mathrm{ICH}+\mathrm{NBP} 25$ groups at both time points $(\mathrm{P}>0.05)$ (Fig. 3).

\section{NBP treatment increased microvascular profiles in rats with ICH}

On microscopical examination, the CD34 antibody labeled very few vascular profiles in the sections prepared from the tissue around the needle track from the Sham operated animals surviving $1 \mathrm{~d}, 3 \mathrm{~d}, 7 \mathrm{~d}$ and $15 \mathrm{~d}$ post operation, respectively (Fig. 4a, upper panels). The amount of labeled microvascular structures appeared to be increased in the ICH groups, and further, in the two drug-treated groups surviving to the above time points

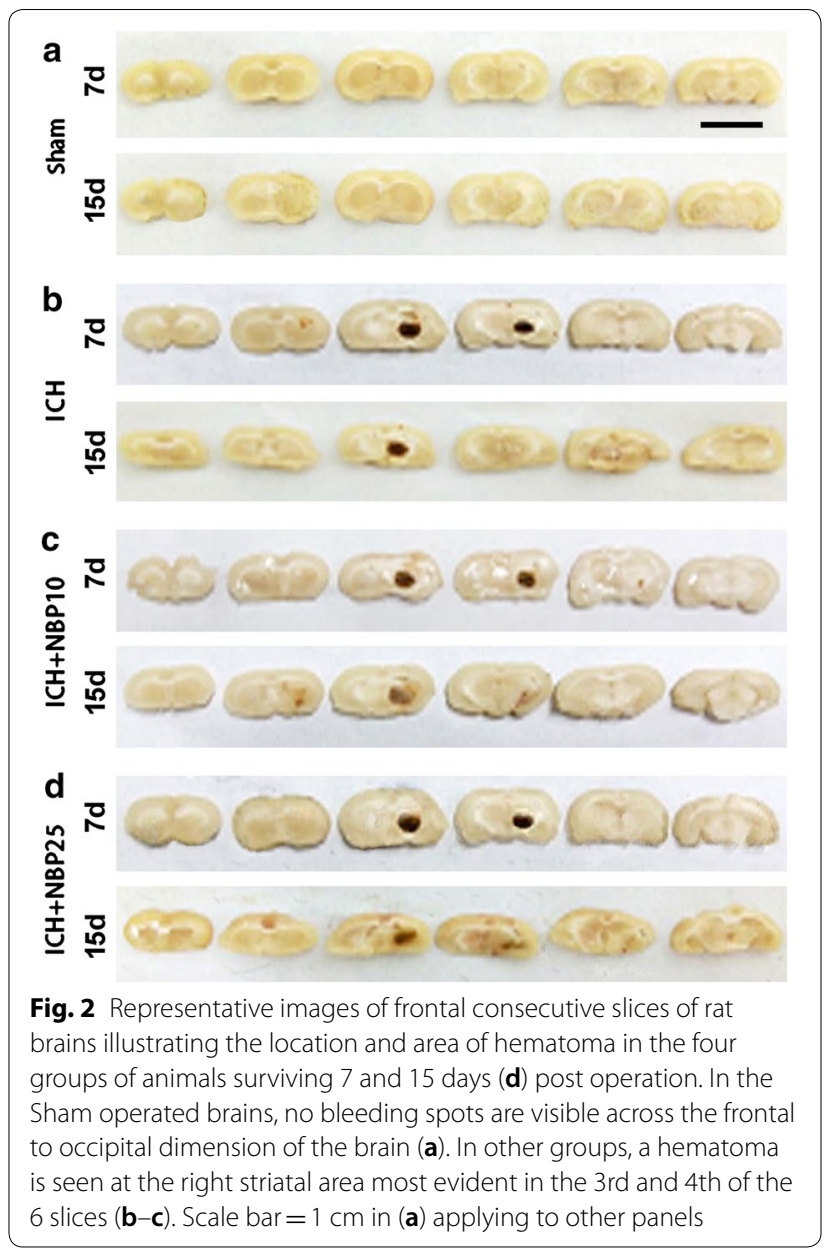

(Fig. 4a, middle and low panels). Specifically, the sections from the $\mathrm{ICH}+\mathrm{NBP} 25$ groups at $7 \mathrm{~d}$ and $15 \mathrm{~d}$ post operation appeared to contain the highest number of the vascular profiles among all groups (Fig. 4a, low right panels).

The numerical density (mean \pm S.D.) of putative new vessels per microscopic field (over a total area of $0.2 \mathrm{~mm}^{2}$ ) was $11.00 \pm 4.14$ in the Sham groups (combining all time point groups as a purpose for standardization). The values were $25.25 \pm 9.91,37.75 \pm 1.78$, $44.50 \pm 0.71$ and $53.00 \pm 4.14$ in the ICH groups at $1 \mathrm{~d}, 3 \mathrm{~d}$, $7 \mathrm{~d}$ and $15 \mathrm{~d}$ time points (same order below), respectively; $39.00 \pm 8.66,49.50 \pm 7.45 ; 56.25 \pm 4.47$ and $64.25 \pm 6.78$ in the ICH $+\mathrm{NBP} 10$ groups; and $48.50 \pm 2.02$, $59.00 \pm 2.83,68.50 \pm 9.90$ and $76.00 \pm 8.18$ groups. Statistically (two-way ANOVA with Bonferroni's post hoc tests), there existed both time $(\mathrm{P}<0.0001, \mathrm{Df}=3, \mathrm{~F}=42)$ and treatment $(\mathrm{P}<0.0001, \mathrm{Df}=3, \mathrm{~F}=287)$ dependent significant effects among the means. Post-hoc tests indicated significant differences for the other groups relative to Sham groups at all time points $(\mathrm{P}<0.01$ to $\mathrm{P}<0.001)$. There were also differences for the $\mathrm{ICH}+\mathrm{NBP} 10$ and 


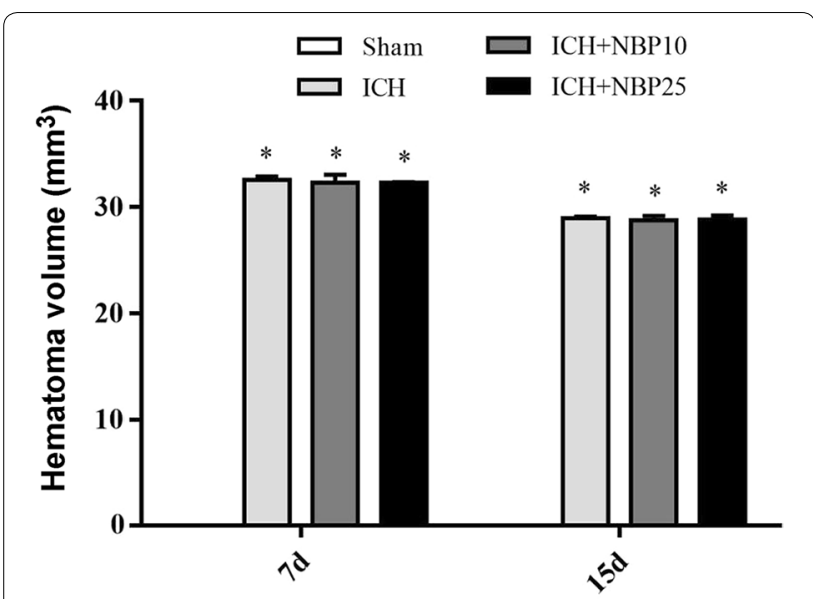

Fig. 3 Quantification of the hematoma in a rat model of $\mathrm{ICH}$ with and without NBP treatments surviving 7 and 15 day post operation. Means are analyzed statistically using ANOVA followed by Bonferroni's Multiple Comparison Test as post hoc. The hematoma volume is minimal in the Sham groups, which is significantly different from the $\mathrm{ICH}, \mathrm{ICH}+\mathrm{NBP} 10$ and $\mathrm{ICH}+\mathrm{NBP} 25$ groups at 7 and 15 days (d) post operation ( $n=5 /$ group/time point, $\left.{ }^{*}: P<0.05\right)$. However, no difference exists for the means between each pair of the $\mathrm{ICH}$, $\mathrm{ICH}+\mathrm{NBP} 10$ and $\mathrm{ICH}+\mathrm{NBP} 25$ groups

$\mathrm{ICH}+\mathrm{NBP} 25$ groups in comparison with $\mathrm{ICH}$ groups at all time points $(\mathrm{P}<0.05$ to $\mathrm{P}<0.001)$. In addition, significant difference was reached between the $\mathrm{ICH}+\mathrm{NBP} 10$ and $\mathrm{ICH}+\mathrm{NBP} 25$ groups at $7(\mathrm{P}<0.01)$ and $15 \mathrm{~d}$ $(\mathrm{P}<0.05)$, respectively (Fig. 4b).

The areal ratios (cross-sectional area of all vascular profiles divided by the field area of the micrograph, expressed as percentage values) were calculated for individual animals and experimental groups. The mean of the vascular fractional area in the $\mathrm{ICH}$ groups (combining the 4 time points) was $1.740 \pm 0.69 \%$. In the $\mathrm{ICH}$ groups, the values were $3.19 \pm 1.65 \%, 4.69 \pm 0.80 \%$, $7.33 \pm 3.73$ and $8.23 \pm 3.75 \%$ at $1 \mathrm{~d}, 3 \mathrm{~d}, 7 \mathrm{~d}$ and $15 \mathrm{~d}$ post operation, respectively. The means in the $\mathrm{ICH}+\mathrm{NBP} 10$ groups were $3.49 \pm 0.32 \%, 6.90 \pm 1.47 \% ; 8.38 \pm 4.53 \%$ and $10.35 \pm 2.76 \%$ at the above surviving time points listed in the same order. The values from the $\mathrm{ICH}+\mathrm{NBP} 25$ groups were $3.52 \pm 0.19 \%, 7.50 \pm 0.16 \% ; 9.58 \pm 1.92 \%$ and $11.93 \pm 2.77 \%$ at these time points. Thus, the vascular areas showed a trend of increase with the increase of surviving time in all groups subjected to blood injections, with the means higher in the two drug-treated than vehicle groups $(\mathrm{P}<0.0001, \mathrm{Df}=3, \mathrm{~F}=42$ for time effect; $\mathrm{P}<0.0001, \mathrm{Df}=3, \mathrm{~F}=287$ for treatment effect). The means of the ICH groups were significantly higher than that of the Sham groups at $7 \mathrm{~d}$ and $15 \mathrm{~d}(\mathrm{P}<0.001)$, and that of the $\mathrm{ICH}+\mathrm{NBP} 10$ and $\mathrm{ICH}+\mathrm{NBP} 25$ groups were increased relative to the Sham groups at $3 \mathrm{~d}, 7 \mathrm{~d}$ and $15 \mathrm{~d}(\mathrm{P}<0.01$ to $\mathrm{P}<0.001)$. Among the drug and vehicle-treated groups, the differences in the means did not reach statistical significance $(P>0.05)$, except for the $\mathrm{ICH}$ vs. ICH $+\mathrm{NBP} 25$ groups at $15 \mathrm{~d}(\mathrm{P}<0.05)($ Fig. $4 \mathrm{c})$.

\section{NBP treatment elevated VEGF and Ang-2 levels in rats with ICH}

To further explore a potential trophic effect of NBP on angiogenesis following $\mathrm{ICH}$, the levels of vascular endothelial growth factor (VEGF) and angiopoietins-2 (Ang-2) in tissue lysates from the injection sites were analyzed by Western blot (Fig. 5a, $\mathrm{n}=5$ /group/time point). The mean o.d. of VEGF in the Sham groups were $0.09 \pm 0.03$ as a baseline (combined groups at all time points). The levels in the $\mathrm{ICH}$ groups were $0.28 \pm 0.02$, $0.48 \pm 0.24,0.52 \pm 0.24$ and $0.68 \pm 0.01$ at $1 \mathrm{~d}, 3 \mathrm{~d}, 7 \mathrm{~d}$ and $15 \mathrm{~d}$, respectively. In the drug-treated animals, the levels were $0.36 \pm 0.19,0.50 \pm 0.12,0.67 \pm 0.14$ and $0.82 \pm 0.13$ in the $\mathrm{ICH}+\mathrm{NBP} 10$, and were $0.44 \pm 0.08,0.63 \pm 0.01$, $0.88 \pm 0.38$ and $0.96 \pm 0.15$ in the $\mathrm{ICH}+\mathrm{NBP} 25$ groups, at the above time points, respectively. Thus, there was a trend of increase in the levels of VEGF in the ICH groups relative to Sham control and in the drug-treated relative to vehicle-treated groups, as indicated by a time $(\mathrm{P}<0.0001, \mathrm{Df}=3, \mathrm{~F}=19)$ and treatment $(\mathrm{P}<0.0001$, $\mathrm{Df}=3, \mathrm{~F}=64$ ) dependent effects. Results from post hoc tests indicated significant differences for all other groups relative to the Sham groups $(\mathrm{P}<0.05$ to $\mathrm{P}<0.0001)$ except for the Sham vs. ICH groups at 1d. The levels of VEGF between $\mathrm{ICH}+\mathrm{NBP} 25$ groups and the $\mathrm{ICH}$ groups were significantly different $(\mathrm{P}<0.05$ and $\mathrm{P}<0.01)$ at $7 \mathrm{~d}$ and $15 \mathrm{~d}$. However, no significant differences were reached for the remaining pairs of means among the $\mathrm{ICH}$ and $\mathrm{ICH}+\mathrm{NBP} 10$ and $\mathrm{ICH}+\mathrm{NBP} 25$ groups (Fig. $5 \mathrm{~b}$ ).

The normalized o.d. of immunoblotted Ang-2 protein in brain lysates were $0.20 \pm 0.01$ as a baseline for the Sham groups. The levels (mean \pm S.D.) were $0.21 \pm 0.01$, $0.43 \pm 0.02,0.48 \pm 0.02,0.48 \pm 0.01$ in the $\mathrm{ICH}$ groups at $1 \mathrm{~d}, 3 \mathrm{~d}, 7 \mathrm{~d}$ and $15 \mathrm{~d}$, respectively. In the $\mathrm{ICH}+\mathrm{NBP} 10$ groups, the means were $0.33 \pm 0.02,0.50 \pm 0.01$, $0.66 \pm 0.02$ and $0.86 \pm 0.01$ at the above time points, respectively. The values were $0.36 \pm 0.02,0.60 \pm 0.02$, $0.91 \pm 0.03$ and $0.99 \pm 0.03$ in the $\mathrm{ICH}+\mathrm{NBP} 25$ groups. There existed a trend of increase in the levels related to the effect of time $(\mathrm{P}<0.0001, \mathrm{Df}=3, \mathrm{~F}=1715)$ as well as treatment $(\mathrm{P}<0.0001, \mathrm{Df}=3, \mathrm{~F}=3441)$ according to two-way ANOVA analysis. Post-hoc tests indicated that there existed significant differences for all blood-injected groups in comparison with the Sham groups at all time points $(\mathrm{P}<0.001)$ except for the Sham vs $\mathrm{ICH}$ groups at $1 d$. There were differences for the $\mathrm{ICH}+\mathrm{NBP} 10$ and $\mathrm{ICH}+\mathrm{NBP} 25$ groups relative to the $\mathrm{ICH}$ groups at all surviving time points $(\mathrm{P}<0.001)$. Furthermore, the levels showed significant differences between the $\mathrm{ICH}+\mathrm{NBP} 10$ 


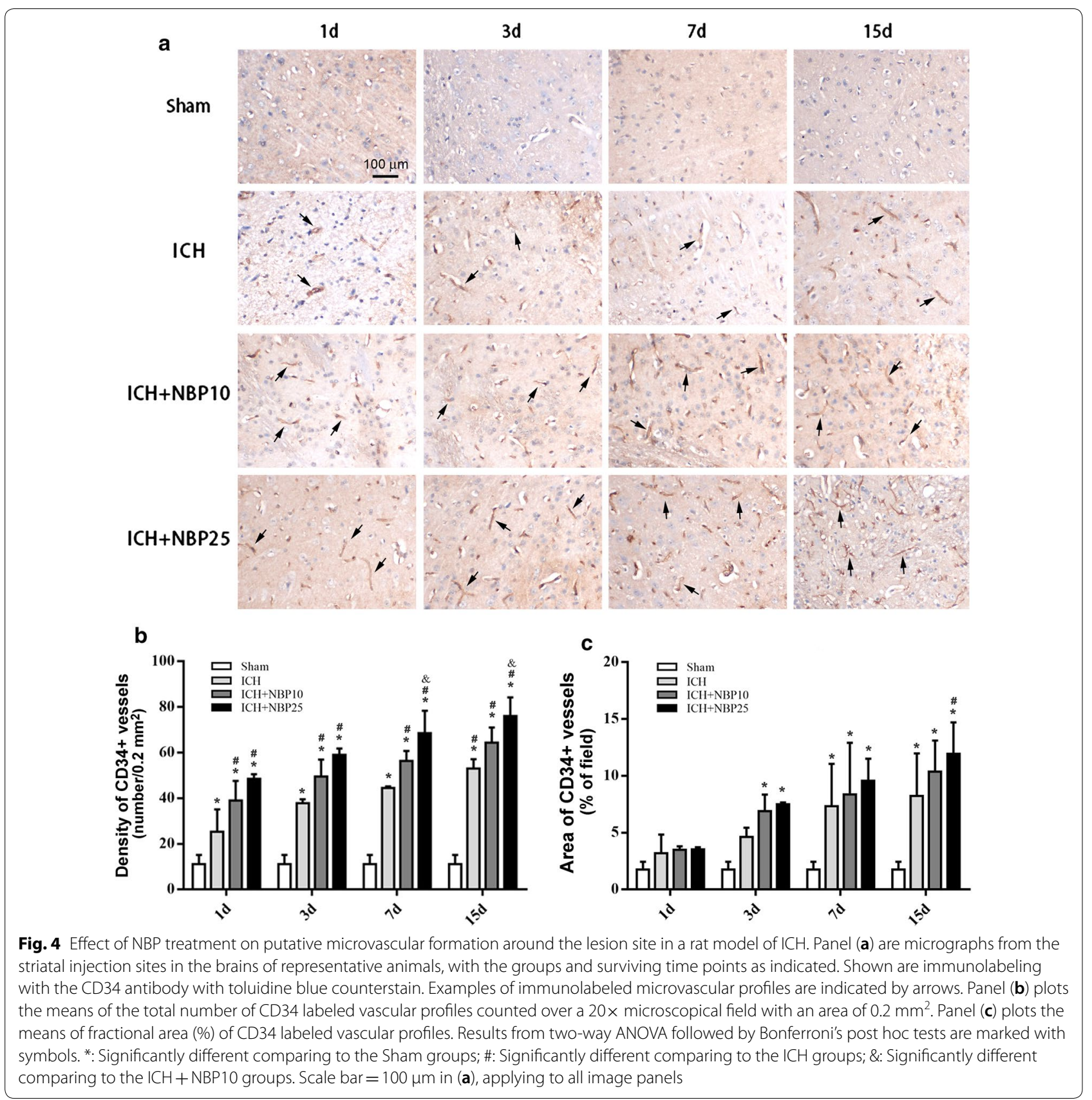

and $\mathrm{ICH}+\mathrm{NBP} 25$ groups at $1 \mathrm{~d}(\mathrm{P}<0.01)$, and at $3 \mathrm{~d}, 7 \mathrm{~d}$ and $15 \mathrm{~d}(\mathrm{P}<0.001)$ as well (Fig. $5 \mathrm{~b})$.

\section{Discussion}

The pathogenesis and pathophysiology underlying $\mathrm{ICH}$ are complex. The space-occupying effect of the hematoma along with blood infiltration into the brain parenchyma could trigger multiple cellular and molecular responses around and beyond the lesion site, such as ischemia, blood-brain barrier disruption, oxidative stress and neuroinflammation, which may result in acute and chronic neuronal damage and neurological dysfunction $[8,12,15]$. Clinical trials suggest that vasospasm of larger brain vessels is not the sole contributor to neurological outcome, and intense efforts have been turned to mechanisms of early brain injury that may play a larger role in functional outcome, including neuroinflammation and microvascular dysfunction [47]. Specifically, the structural and functional disruption of neurovascular unit (NVU) may be critically involved in the pathogenesis 


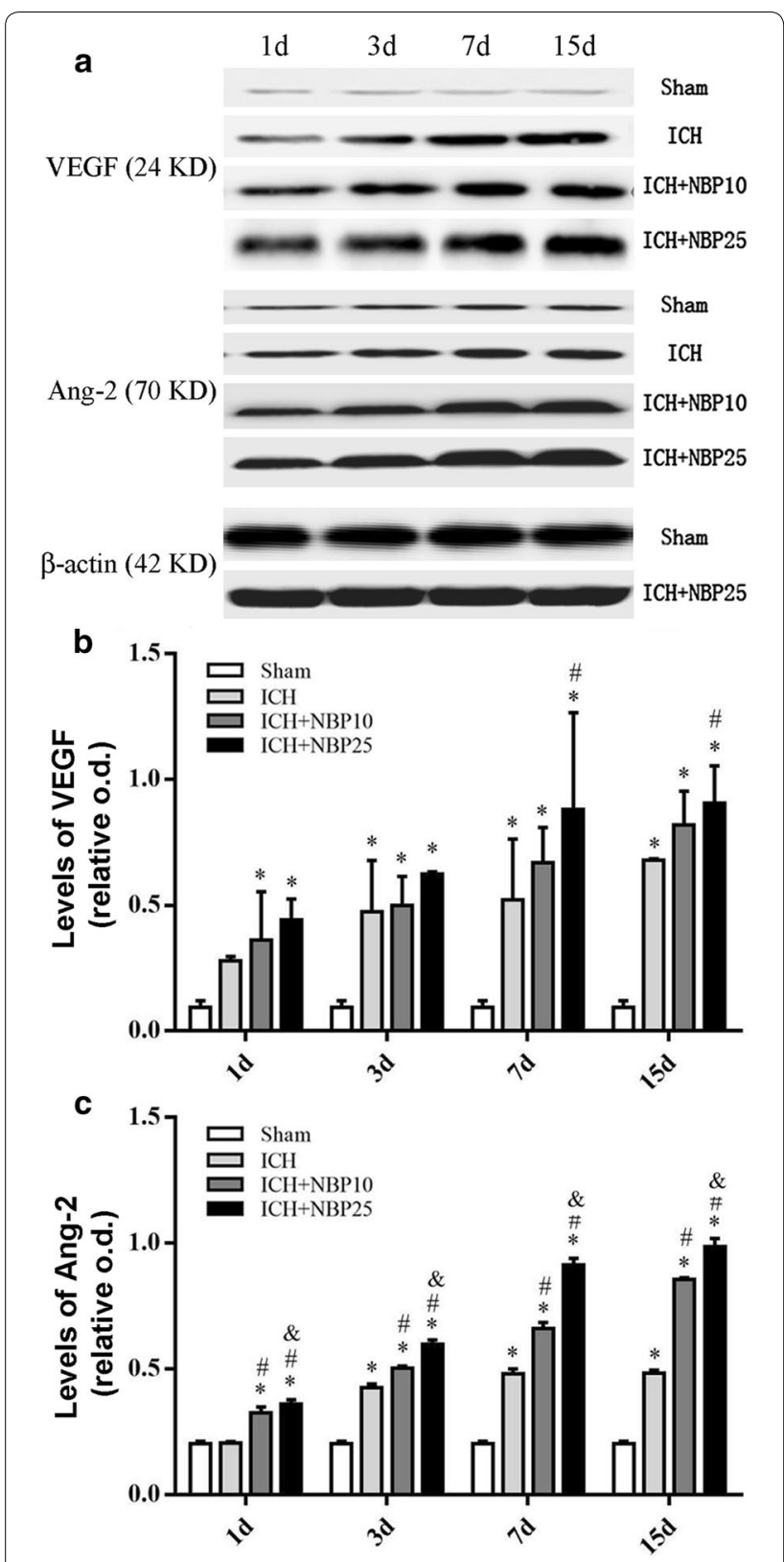

Fig. 5 Effect of NBP treatment on the expression of the vascular endothelial growth factor (VEGF) and angiopoietins-2 (Ang-2) proteins in tissue lysates of the injection site in a rat model of $\mathrm{ICH}$. Panel (a) shows representative immunoblot images (upper two sets) of VEGF and Ang-2 in the groups as indicated, with representative images (bottom set) showing equal protein loading as blotted with the $\beta$-actin antibody. Panels $(\mathbf{b}, \mathbf{c})$ plot the protein levels expressed as relative optic densities (o.d.) normalized to the internal control $\beta$-actin. Results from two-way ANOVA followed by Bonferroni's post hoc tests are marked with symbols, with * indicating significantly different comparing to the Sham groups; \# indicating significantly different comparing to the ICH groups; and \& indicating significantly different comparing to the $\mathrm{ICH}+\mathrm{NBP} 10$ groups of cerebral stroke [17]. NVU is structurally related to neuronal and neuroglial cells, as well as microvascular endothelial cells, smooth muscle cells, pericytes and the extracellular matrix [18-22]. Thus, through tightly regulated multidirectional molecular signaling, the NVU is considered to be involved in many key processes critical for functional neurovascular coupling, including via a response of angiogenesis. Thus, the formation of new blood vessels from existing vasculature in the peri-infarct or perihemorrhagic zone is considered important for neurological recovery after ischemic or hemorrhagic cerebral stroke [23-26]. Accordingly, promoting angiogenesis represents a novel therapeutic strategy in clinical management of stroke patients.

Since the approval by the China Food and Drug Administration for the treatment of ischemic stroke, NBP has been clinically used in the management of patients with ischemic cerebrovascular diseases [32-34]. Experimental studies have identified multiple potential neuroprotective effects of this compound, such as increasing blood perfusion to the ischemic area, preventing blood brain barrier disruption, protecting mitochondria, inhibiting nerve cell apoptosis, scavenging oxygen free radicals, suppressing inflammation and reducing cerebral edema in animal models of cerebral ischemia [36-45, 47-49]. It should be noted that precautions were (and still remain) recommended for the prescription of this drug to patients with hemorrhagic stroke because of a concern of re-bleeding side-effect. However, to the best of our knowledge, no data from human clinical or animal studies are yet available to confirm this adverse effect. In this regard, the pharmacological efficacy or toxicity, if any, of NBP on hemorrhagic cerebral stroke, and the mechanism thereof, deserves experimental investigation.

Several rodent models of ICH are commonly used for basic and translational studies on hemorrhagic cerebral stroke in humans, including perforation of cerebral arteries, and intracranial or intracerebral injection of selfblood [50-53]. The effects of the lesions and experimental interventions could be addressed using various batteries of neurobehavioral tests along with different morphological and biochemical measurements. The intra-striatal blood injection model was used in this study to induce $\mathrm{ICH}$, which mimics the internal capsule stroke commonly seen in humans in the clinic. One advantage of this model is that the post-operational animal surviving rate is relatively high comparing to other models with more severe or extensive intracranial bleeding. Unilateral injection of autologous blood into the globus pallidus causes acute neurological deficits largely involving motor dysfunctions contralateral to the injection side in the experimental rats, which could be assessed using the Longa scoring method. Notably, as with other rodent models of cerebral 
stroke or trauma, neurological deficits in rats subjected to this lesion progress with an initial severe phase followed by a "natural" or spontaneous trend of functional recovery [54]. In the present study, motor deficits in rats subjected to intra-striatal blood injection as indicated by Longa scoring occurred apparently at the 3rd day post operation. The deficits in both the $\mathrm{ICH}+\mathrm{NBP} 10$ and $\mathrm{ICH}+\mathrm{NBP} 25$ groups appeared to be milder than that in the vehicle controls as observed from 1 to 15 days post operation, with signs of recovery also occurred earlier in the drug-treated animals (starting as early as the first day post operation). These findings suggest that NBP treatment with a dosage $10-25 \mathrm{mg} / \mathrm{kg}$ Bid can promote an earlier functional recovery in rats subjected to the current experimentally induced $\mathrm{ICH}$. It should be noted that the volumes of hematoma remained comparable between the $\mathrm{ICH}, \mathrm{ICH}+\mathrm{NBP} 10$ and $\mathrm{ICH}+\mathrm{NBP} 25$ groups. Therefore, this drug does not appear to promote the clearance of the injected blood in the brain parenchyma.

As denoted precedingly, neovascularization is stimulated in the brain following ischemic or hemorrhagic insults especially in the periinfarct or perihemorrhagic zone, which may represent a positive neurorepair process for functional neurological recovery [23-26]. Upregulation of many molecules, including some soluble factors, is involved in such a process. The highly glycosylated type I transmembrane glycoprotein CD34 is a molecular marker for neovascularization because it is selectively expressed on the hematopoietic stem or progenitor cells as well as the progenitor or differentiating endothelial cells in humans and other mammals, with its expression down-regulated to undetectable levels in mature vascular cells [55-58]. VEGF is a highly conserved dimer glycoprotein serving as a soluble mitogenic factor specifically for vascular endothelial cells. It helps create new blood vessels during embryonic development, and also is key to the formation of collateral circulation to bypass blocked vessels in diseased conditions in adult organisms. After binding to its receptors VEGFR-1 and VEGFR-2, the tyrosine kinase is activated, resulting in calcium inflow in the cells. This signaling can facilitate the proliferation and differentiation of endothelial cells, and also enhance the permeability of vascular endothelial cells to form temporary extracellular matrix, thereby collectively promoting angiogenesis $[59,60]$. In healthy adult brain, VEGF is expressed at low levels and is only sporadically detectable in most brain regions [61]. Following ischemic or hypoxic insults, VEGF expression in the brain or the periphery is upregulated to stimulate endothelial cell proliferation and formation of new blood vessels [6264]. Ang-2 is another important soluble factor for angiogenesis. This protein is also highly expressed in tissues during embryonic development, and remains expressed at minimal levels in endothelial cells at adulthood under normal conditions [65-67]. Ang-2 can facilitate the response of vascular endothelial cells to VEGF [67]. The synergistic effect of these two factors provides a strong support to neovascularization following various central and peripheral injuries or vascular blockage [61-65]. In addition, both factors can play a pathogenic role in the malignant growth of tumors that depends on blood supply via angiogenesis [66-69].

In the present study, the numerical density of putative new microvascular profiles was increased in the $\mathrm{ICH}$ relative to Sham groups post operation during the observation time period. NBP treatments at the two selected doses could increase the amount of these microvascular profiles in the perihemorrhagic zone. The fractional areas of vascular profiles were increased in the ICH relative to Shame groups. While a trend of increase in the vascular area also occurred in the drug-treated groups, the effect between the drug and vehicle-treated groups did not reach statistical significance at most of the time points examined (except for the $\mathrm{ICH}+\mathrm{NBP} 25$ vs. ICH at 7 and $15 \mathrm{~d}$ ). The lack of a full parallelism between the increases of vascular number and area might be related to the transient expression of CD43 in endothelial cells during angiogenesis, which could limit the increase of the sum area of the new microvasculature. The elevation of VEGF and Ang-2 levels in the ICH relative to Sham groups is consistent with a lesion response [61-67]. Importantly, the levels of these two angiogenic factors were significantly higher in the drug-treated than the vehicle-treated groups at most surviving time points (i.e., VEGF in the $\mathrm{ICH}$ vs. $\mathrm{ICH}+\mathrm{NBP} 25$ groups at $7 \mathrm{~d}$ and $15 \mathrm{~d}$, and Ang-2 in the $\mathrm{ICH}$ vs. the $\mathrm{ICH}+\mathrm{NBP} 10$ and $\mathrm{ICH}$ vs. $\mathrm{ICH}+\mathrm{NBP} 25$ groups at all surviving time points). Together, the morphological and biochemical data from this study support the notion that NBP treatment at $10-25 \mathrm{mg} / \mathrm{kg}$ Bid can promote neovascularization in the perihemorrhagic zone in the current model of experimental ICH.

\section{Conclusions}

The present study shows that in a rat model of $\mathrm{ICH}$ via intra-striatal injection of autologous blood, NBP administration at 10 and $25 \mathrm{mg} / \mathrm{kg}$ Bid can significantly mitigate motor deficits and allow an earlier neurological recovery. Importantly, NBP treatment can promote neovascularization around the lesion site potentially related to the upregulation of VEGF and Ang-2. Clinical use of this drug among patients with cerebral hemorrhage might be beneficial for poststroke neurological recovery. 


\section{Methods}

\section{Animals}

Male Sprague-Dawley rats weighting $210 \pm 20 \mathrm{~g}$ and aged 8-12 weeks-old were obtained from the Dongtang Animal Center of Hunan University of Traditional Chinese Medicine. Rats were maintained in their vivarium under programmed control of temperature $\left(23 \pm 2{ }^{\circ} \mathrm{C}\right)$, humidity $(50 \pm 5 \%)$ and illumination (12/12 h light/dark cycle), with standard rodent chews and water freely accessible during the entire experimental period.

\section{Surgery and drug administration}

$\mathrm{ICH}$ was surgically induced according to the method described by Rosenberg et al. [70]. Briefly, rats were anesthetized with sodium pentobarbital at a dosage of $50 \mathrm{mg} / \mathrm{kg}$ via intraperitoneal (i.p.) injection, and placed on a stereotaxic apparatus, with craniotomy performed under sterile conditions. Approximately $0.2 \mathrm{ml}$ autologous whole blood was drawn from the femoral artery. Subsequently, $100 \mu \mathrm{l}$ semi-coagulated blood was injected into the right globus pallidus slowly using the following coordinates: $1 \mathrm{~mm}$ posterior to Bregma, $3 \mathrm{~mm}$ lateral to the sagittal suture and $5.5 \mathrm{~mm}$ below skull surface. The needle was maintained in place for an additional $5 \mathrm{~min}$ following the infusion to prevent backflow, and then withdrawn slowly. The skull hole was sealed with bone wax, and the skin incision was closed with sutures. Rats in the Sham group were injected with sterile physiological saline instead of blood following the same surgical procedure. During surgery the animal was placed on a warm water bag to maintain body temperature. After operation, rats were kept warm in a cage under a $60 \mathrm{~W}$ incandescent lamp until they fully recovered from anesthesia, followed by an initial verification of the occurrence of neurological deficits using the Longa's scoring method [54]. The animals that did not exhibit neurological deficits $(n=24)$ or died $(n=17$ in total $)$ during the experiments were discarded from this study.

NBP was purchased from Shijiazhuang Pharmaceutical Co., Ltd (Hebei, China). It was dissolved in soybean oil for oral gavage. The animals were randomly divided into: (1) sham-operated group (Sham group, $n=40$ ) (2) $\mathrm{ICH}$ model group receiving soybean oil only as vehicle control (ICH group, $\mathrm{n}=40$ ), (3) low dosage NBP treatment animals $(\mathrm{ICH}+\mathrm{NBP} 10$ group, $\mathrm{n}=40)$ that were subjected to $\mathrm{ICH}$ induction and fed with NBP10 at $10 \mathrm{mg} / \mathrm{kg} / \mathrm{Bid}$, and (4) moderate NBP dosing group ( $\mathrm{ICH}+\mathrm{NBP} 25$ group, $\mathrm{n}=40$ ) consisted of operated animals receiving $\mathrm{NBP}$ at $25 \mathrm{mg} / \mathrm{kg} / \mathrm{Bid}$. These two dosages were chosen in reference to previous rodent studies [36-40]. NBP was dosed first approximately $4 \mathrm{~h}$ before the animals were anesthetized for surgery, and until the day they were euthanatized with a killing dose $(100 \mathrm{mg} / \mathrm{kg}$, i.p. $)$ of sodium pentobarbital for terminal brain examination. Behavioral test and brain examination were carried out at 1, 3, 7 and 15 days (d) after operation, respectively.

\section{Assessment of neurological deficits}

Neurobehavioral assessment was conducted on control and drug-treated animals ( $\mathrm{n}=10$ /group/time point) according to the Longa's scoring method [54]. Thus, a score 0 was defined if the animal showed no any movement abnormality. Score 1 was given when the animal could not fully extend its left forelimb. Score 2 was recorded if the animal rotated to the left side while walking. Score 3 was given if the animal dumped to the left side while walking. Score 4 was noted if the animal could not walk on its own, but remained consciously alert.

\section{Measurement of hematoma volume}

Hematoma volume in the brain was estimated using equally spaced coronal cerebral slices $(n=5 /$ group/time point). Thus, after removal from the skull, the brain was serially sliced at the coronal plane with $1 \mathrm{~mm}$ intervals. Images of consecutive slices (up to 6) together with a ruler were taken with a digital camera and saved as a TIF file. The area of hematoma in each slice (expressed as A1, A2,...A6) was measured on computer screen at high resolution using the NIH image J software. The total volume of hematoma in each brain was calculated according to the following formula: $\mathrm{V}=\mathrm{t} \times(\mathrm{A} 1+\mathrm{A} 2, \ldots+\mathrm{A} 6) \mathrm{mm}^{3}$, wherein $V$ refers to the volume of the hematoma, $t$ is the thickness of the brain slice, and A1, A2,...A6 are the areas of hematoma measured in consecutive slices.

\section{Microscopical study of microvasculature}

Histology and immunohistochemical labeling with a CD34 antibody, a marker for newly formed blood vessels [55-58], were applied to determine the potential effect of NBP treatment in promoting neovascularization. After behavioral test and brain collection $(n=5 /$ group/time point), a tissue block covering the hematoma and its surrounding region was dissected out from the slice with the most visible bleeding site. Tissue blocks were then fixed in formalin, dehydrated in ascending concentrations of ethanol, permeabilized in xylene and embedded in wax. Paraffin Sections (5 $\mu \mathrm{m}$-thick) were then prepared, and subjected to immunohistochemistry to visualize CD34 labeled blood vessels.

Immunolabeling was initiated with a process of dewaxing with xylene and rehydration with descending concentrations of ethanol until rinses with phosphate-buffered saline (PBS, $0.1 \mathrm{M}, \mathrm{pH}=7.3$ ). Sections were then treated with $5 \% \mathrm{H}_{2} \mathrm{O}_{2}$ in PBS for $30 \mathrm{~min}$, and incubated in a PBS buffer containing 5\% normal rabbit serum and $0.3 \%$ 
Triton X-100 for $1 \mathrm{~h}$ (h). Sections were further incubated with the above buffer solution containing the rabbit antimouse CD34 antibody (1:500, ab185732, Abcam Trading Shanghai Company Ltd, Shanghai, China) at $4{ }^{\circ} \mathrm{C}$ overnight. On the next day, the sections were reacted with biotinylated rabbit anti-mouse IgG at 1:400 for $1 \mathrm{~h}$, and further with the avidin-biotin complex $(\mathrm{ABC})$ reagents (1:400) (Vector Laboratories, Burlingame, CA, USA) for $1 \mathrm{~h}$. The final immunoreactive product was visualized in PBS with $0.003 \% \mathrm{H}_{2} \mathrm{O}_{2}$ and $0.05 \%$ 3,3'-diaminobenzidine. Three rinses with PBS were used between the incubations. Sections were then counterstained lightly with toluidine blue, dehydrated with ethanol, cleared with xylene, and coverslippered before microscopical examination.

\section{Western blot for angiogenic markers}

Immunoblotting was used to detect potential changes in the levels of two important angiogenesis related proteins, i.e., VEGF and angiopoietins-2 (Ang-2) [40, 46]. Brains from the rats in the drug-treated and control groups surviving to all timed points were subjected to this analysis ( $n=5 /$ group/time point). Following consecutive brain slicing, tissue blocks surrounding the hematoma in the right globus pallidus were excised, carefully isolated, snap-frozen in liquid nitrogen, and stored at $-80 \mathrm{C}$ until use. The samples were then homogenized on ice by sonication in T-PER extraction buffer (Pierce, Rockford, IL, USA) containing a cocktail of protease inhibitors (Roche, Indianapolis, IN, USA). The supernatants were collected following centrifuge of the tissue extracts at $15,000 \mathrm{~g}$ at $4{ }^{\circ} \mathrm{C}$, with protein concentrations determined using the BCA assay. Supernatants containing equal amount of total protein were run in SDS-polyacrylamide gels. Separated proteins were electrotransferred to Trans-Blot pure nitrocellulose membranes. The membranes were then incubated overnight at $4{ }^{\circ} \mathrm{C}$ with a rabbit antibody against recombinant human VEGF (D151121, 1:1000, Sangon Biotech. Co., Ltd. Shanghai, China), a rabbit anti-Ang-2 polyclonal antibody (ab139947, 1:1000, Abcam Trading Shanghai Company Ltd, Shanghai, China), and a rabbit anti- $\beta$-actin antibody as loading control (PA1-16889, 1:5000, ThermoFisher Trading Shanghai Company Ltd, Shanghai, China), respectively. The membranes were further reacted with horseradish peroxidase (HRP) conjugated goat anti-rabbit IgG (1:10000; Bio-Rad Laboratories). Immunoblot signal was visualized with the ECL-Plus detection kit according to manufacturer's instruction (Thermo Fisher Scientific Trading Shanghai Company Ltd, Shanghai, China), followed by X-ray film exposure, film development and image capture using a laser scanner.

\section{Imaging acquisition and data analysis}

CD34 immunolabeled sections were examined on an Olympus (BX60) microscope equipped with a digital camera and an image analysis system (Optronics, Goleta, CA). Putative new blood vessels appearing as funicular or circular hollow profiles were identifiable at low magnification. For morphometry, images (with a total microscopic field area of $0.2 \mathrm{~mm}^{2}$ ) were taken using the $20 \times$ objective lens over the areas approximately at the $12,3,6$, and 9 clock points relative to the center of needle track or the hematoma. Vascular profiles consisted of individual endothelial cells or endothelial cell clusters were counted, whereas larger profiles with a lumen greater than eight red blood cell's diameter were not included in the counting. The newly formed vascular profiles as defined above were also marked and subjected to fractional area measurements, which were carried out using the NIH image J software. The fractional area of the blood vessels was calculated for each micrograph using square millimeter as the unit area. Data were recorded into Excel Spreadsheets, with averaged values for individual brains, and further, means and standard deviations for individual animal groups, calculated. Images of immunoblotted protein bands were also analyzed using the image J software. The optic densities (o.d.) of the VEGF and Ang-2 bands were standardized to that of the $\beta$-actin as internal control, and expressed as density ratios.

\section{Statistical tests and figure preparation}

Experimental data were presented as mean \pm standard deviation (mean $\pm S D$ ). Statistical tests were performed using the GraphPad Prism 5.1 (San Diego, CA, USA) software package. Data were analyzed with two-way ANOVA along with Bonferroni multi-group comparison as post hoc tests (reflecting the effects of time and treatment variables and their reaction), with the minimal level of significant difference set at $\mathrm{P}<0.05$. All figures were assembled using Photoshop 7.1.

\footnotetext{
Abbreviations

NBP: DI-3-n-Butylphthalide; ICH: Intracerebral hemorrhage; PHZ: Perihemorrhagic zone; NVU: Neurovascular unit; VEGF: Vascular endothelial growth factor; Ang-2: Angiopoietins-2; NIH: National Institutes of Health; PBS: Phosphatebuffered saline; ABC: Avidin-biotin complex; BCA: Bicinchoninic acid; SDS: Sodium dodecyl sulfate; HRP: Horseradish peroxidase.

\section{Acknowledgements}

The authors thank Zhi-Gao Ding for technical assistance.

Authors' contributions

ET conceived the study, organized in its design, coordination, and data analysis, and wrote the manuscript. QC, LT and YW carried out the experiments and data acquisition. All authors read and approved the final manuscript.
} 


\section{Funding}

This study was supported by Hunan Provincial Development and Reform Commission [Project Xiang Gai Gao Ji \#1493, 2012 to E.T.]. The funding body was not involved in the design of the study, in the collection, analysis and interpretation of data, and in writing the manuscript.

\section{Availability of data and materials}

The datasets used and/or analyzed during the current study are available from the corresponding author on reasonable request.

\section{Ethics approval and consent to participate}

All applicable international, national, and/or institutional guidelines for the care and use of animals were followed. The animal study protocol (ref\#2017044) was approved by the Ethics Committee of the Brain Hospital of Hunan Province in compliance with the National Institutes of Health $(\mathrm{NIH})$ Guide for the Care and Use of Laboratory Animals.

\section{Consent for publication}

Not applicable.

\section{Competing interests}

The authors declare that the research was conducted in the absence of any commercial or financial relationships that could be construed as a potential competing interest.

\section{Author details}

1 Department of Neurology, Hunan Brain Hospital, Hunan University of Chinese Medicine, Changsha 410208, Hunan, China. ${ }^{2}$ Department of Neurology, The Fourth Hospital of Changsha, Changsha 410006, Hunan, China.

Received: 3 March 2020 Accepted: 20 May 2020

Published online: 29 May 2020

\section{References}

1. Donkor ES. Stroke in the 21st century: a snapshot of the burden, epidemiology, and quality of life. Stroke Res Treat. 2018;2018:3238165.

2. Kalkonde YV, Alladi S, Kaul S, Hachinski V. Stroke prevention strategies in the developing world. Stroke. 2018;49:3092-7.

3. Pandian JD, Gall SL, Kate MP, Silva GS, Akinyemi RO, Ovbiagele BI, et al. Prevention of stroke: a global perspective. Lancet. 2018;392:1269-78.

4. Wang Y, Li Z, Wang Y, Zhao X, Liu L, Yang X, et al. Chinese Stroke Center Alliance: a national effort to improve healthcare quality for acute stroke and transient ischaemic attack: rationale, design and preliminary findings. Stroke Vasc Neurol. 2018;3:256-62.

5. Wu S, Wu B, Liu M, Chen Z, Wang W, Anderson CS, et al. China stroke study collaboration. Stroke in China: advances and challenges in epidemiology, prevention, and management. Lancet Neurol. 2019;18:394-405.

6. Qureshi Al, Tuhrim S, Broderick JP, Batjer HH, Hondo H, Hanley DF. Spontaneous intracerebral hemorrhage. N Engl J Med. 2001;344:1450-60.

7. Aronowski J, Zhao X. Molecular pathophysiology of cerebral hemorrhage: secondary brain injury. Stroke. 2011;42:1781-6.

8. Prabhakaran S, Naidech AM. Ischemic brain injury after intracerebral hemorrhage: a critical review. Stroke. 2012;43:2258-63.

9. Hackenberg KAM, Hänggi D, Etminan N. Unruptured intracranial aneurysms. Stroke. 2018;49:2268-75.

10. Gross BA, Jankowitz BT, Friedlander RM. Cerebral intraparenchymal hemorrhage: a review. JAMA. 2019;321:1295-303.

11. Jusufovic M, Berge TE, Guo R, You S, Delcourt C, Anderson C, et al. Effects of candesartan in the acute phase of intracerebral hemorrhage. J Stroke Cerebrovasc Dis. 2019;28:2262-7.

12. Gavito-Higuera J, Khatri R, Qureshi IA, Maud A, Rodriguez GJ. Aggressive blood pressure treatment of hypertensive intracerebral hemorrhage may lead to global cerebral hypoperfusion: case report and imaging perspective. World J Radiol. 2017;9:448-53.

13. Anderson CS, Huang Y, Lindley RI, Chen X, Arima H, Chen G, et al. Intensive blood pressure reduction with intravenous thrombolysis therapy for acute ischaemic stroke (ENCHANTED): an international, randomised, open-label, blinded-endpoint, phase 3 trial. Lancet. 2019;393:877-88.
14. Bouasquevisque DS, Benavente OR, Shoamanesh A. Antiplatelet therapy in cerebral small vessel disease. Curr Neurol Neurosci Rep. 2019;19:61.

15. Hostettler IC, Seiffge DJ, Werring DJ. Intracerebral hemorrhage: an update on diagnosis and treatment. Expert Rev Neurother. 2019;19:679-94.

16. Khattar NK, Bak E, White AC, James RF. Heparin treatment in aneurysmal subarachnoid hemorrhage: a review of human studies. Acta Neurochir Suppl. 2020;127:15-9.

17. ladecola $C$. The neurovascular unit coming of age: a journey through neurovascular coupling in health and disease. Neuron. 2017;96:17-42.

18. Venkatasubramanian C, Mlynash M, Finley-Caulfield A, Eyngorn I, Kalimuthu R, Snider RW, et al. Natural history of perihematomal edema after intracerebral hemorrhage measured by serial magnetic resonance imaging. Stroke. 2011;42:73-80.

19. Wu TY, Sharma G, Strbian D, Putaala J, Desmond PM, Tatlisumak T, et al. Natural history of perihematomal edema and impact on outcome after intracerebral hemorrhage. Stroke. 2017;48:873-9.

20. Haque ME, Gabr RE, George SD, Zhao X, Boren SB, Zhang X, et al. Serial metabolic evaluation of perihematomal tissues in the intracerebral hemorrhage pig model. Front. Neurosci. 2019;13:888.

21. Ironside N, Chen CJ, Ding D, Mayer SA, Connolly ES Jr. Perihematomal edema after spontaneous intracerebral hemorrhage. Stroke. 2019;50:1626-33.

22. Peng WJ, Li Q, Tang JH, Reis C, Araujo C, Feng R, et al. The risk factors and prognosis of delayed perihematomal edema in patients with spontaneous intracerebral hemorrhage. CNS Neurosci Ther. 2019;25:1189-94.

23. Krupinski J, Kaluza J, Kumar P, Kumar S, Wang JM. Role of angiogenesis in patients with cerebral ischemic stroke. Stroke. 1994;25:1794-8.

24. Kim H, Edwards NJ, Choi HA, Chang TR, Jo KW, Lee K. Treatment strategies to attenuate perihematomal edema in patients with intracerebral hemorrhage. World Neurosurg. 2016;94:32-41.

25. Pías-Peleteiro J, Pérez-Mato M, López-Arias E, Rodríguez-Yáñez M, Blanco M, Campos F, et al. Increased endothelial progenitor cell levels are associated with good outcome in intracerebral hemorrhage. Sci Rep. 2016;6:28724.

26. Fischer M, Schiefecker A, Lackner P, Frank F, Helbok R, Beer R, et al. Targeted temperature management in spontaneous intracerebral hemorrhage: a systematic review. Curr Drug Targets. 2017;18:1430-40.

27. Li Y, Zhong W, Jiang Z, Tang X. New progress in the approaches for blood-brain barrier protection in acute ischemic stroke. Brain Res Bull. 2019;144:46-57.

28. Efferth T, Zacchino S, Georgiev MI, Liu L, Wagner H, Panossian A. Nobel Prize for artemisinin brings phytotherapy into the spotlight. Phytomedicine. 2015;22:A1-3.

29. Cai Y, Zhang CS, Liu S, Wen Z, Zhang AL, Guo X, et al. Add-on effects of Chinese herbal medicine for post-stroke spasticity: a systematic review and meta-analysis. Front Pharmacol. 2019;10:734.

30. Wang $\mathrm{HL}$, Zeng $\mathrm{H}$, Xu MB, Zhou XL, Rong PQ, Jin TY, et al. Efficacy and safety of Chinese herbal medicine for primary intracerebral hemorrhage: a systematic review of randomized controlled trials. Front Pharmacol. 2019;10:1139.

31. Zeng L, Tang G, Wang J, Zhong J, Xia Z, Li J, et al. Safety and efficacy of herbal medicine for acute intracerebral hemorrhage (CRRICH): a multicentre randomised controlled trial. BMJ Open. 2019;9:e024932.

32. Abdoulaye IA, Guo YJ. A review of recent advances in neuroprotective potential of 3-N-Butylphthalide and its derivatives. Biomed Res Int. 2016;2016:5012341.

33. Wang $S$, Ma F, Huang L, Zhang Y, Peng Y, Xing C, et al. Dl-3-n-Butylphthalide (NBP): a promising therapeutic agent for ischemic stroke. CNS Neurol Disord Drug Targets. 2018;17:338-47.

34. Xu ZQ, Zhou Y, Shao BZ, Zhang JJ, Liu C. A systematic review of neuroprotective efficacy and safety of DL-3-N-Butylphthalide in ischemic stroke. Am J Chin Med. 2019;47:507-25.

35. Zhou H, Ye M, Xu W, Yu M, Liu X, Chen Y. DL-3-n-butylphthalide therapy for Parkinson's disease: a randomized controlled trial. Exp Ther Med. 2019;17:3800-6.

36. Ye ZY, Xing HY, Wang B, Liu M, Lv PY. DL-3-n-butylphthalide protects the blood-brain barrier against ischemia/hypoxia injury via upregulation of tight junction proteins. Chin Med J (Engl). 2019;132:1344-53.

37. Hu J, Wen Q, WuY, Li B, Gao P. The effect of butylphthalide on the brain edema, blood-brain barrier of rats after focal cerebral infarction and the expression of Rho A. Cell Biochem Biophys. 2014;69:363-8. 
38. Du R, Teng JF, Wang Y, Zhao XY, Shi ZB. Clinical study of Butylphthalide combined with Xue Shuan Tong on serum inflammatory factors and prognosis effect of patients with cerebral infarction. Pak J Pharm Sci. 2015;28(5 Suppl):1823-7.

39. He Z, Zhou Y, Huang Y, Wang Q, Zheng B, Zhang H, et al. Dl-3-n-butylphthalide improves functional recovery in rats with spinal cord injury by inhibiting endoplasmic reticulum stress-induced apoptosis. Am J Transl Res. 2017;9:1075-87.

40. Tang SC, Luo CJ, Zhang KH, Li K, Fan XH, Ning LP, et al. Effects of dl-3-nbutylphthalide on serum VEGF and bFGF levels in acute cerebral infarction. Eur Rev Med Pharmacol Sci. 2017;21:4431-6.

41. Yang XD, Cen ZD, Cheng HP, Shi K, Bai J, Xie F, et al. L-3-n-butylphthalide protects HSPB8 K141N mutation-induced oxidative stress by modulating the mitochondrial apoptotic and Nrf2 pathways. Front Neurosci. 2017;11:402.

42. Zhao YJ, Nai Y, Ma QS, Song DJ, Ma YB, Zhang LH, et al. Dl-3-n-butylphthalide protects the blood brain barrier of cerebral infarction by activating the Nrf-2/HO-1 signaling pathway in mice. Eur Rev Med Pharmacol Sci. 2018;22:2109-18.

43. Cheng X, Wang H, Liu C, Zhong S, Niu X, Zhang X, et al. Dl-3-n-butylphthalide promotes remyelination process in cerebral white matter in rats subjected to ischemic stroke. Brain Res. 2019;1717:167-75.

44. Han QY, Zhang H, Zhang X, He DS, Wang SW, Cao X, et al. dl-3-nbutylphthalide preserves white matter integrity and alleviates cognitive impairment in mice with chronic cerebral hypoperfusion. CNS Neurosci Ther. 2019;25:1042-53.

45. Qin C, Zhou P, Wang L, Mamtilahun M, Li W, Zhang Z, et al. Dl-3-Nbutylphthalide attenuates ischemic reperfusion injury by improving the function of cerebral artery and circulation. J Cereb Blood Flow Metab. 2019;39:2011-21.

46. Li W, Wei D, Xie X, Liang J, Song K, Huang L. DI-3-n-Butylphthalide regulates the Ang-1/Ang-2/Tie-2 signaling axis to promote neovascularization in chronic cerebral hypoperfusion. Biomed Pharmacother. 2019;113:108757.

47. Geraghty JR, Davis JL, Testai FD. Neuroinflammation and microvascular dysfunction after experimental subarachnoid hemorrhage: emerging components of early brain injury related to outcome. Neurocrit Care. 2019;31:373-89.

48. Zhao Y, Li J, Zhang P, Chen C, Li S. Protective effects of dl-3n-butylphthalide against diffuse brain injury. Neural Regen Res. 2013;8:2615-24.

49. Zheng B, Zhou Y, Zhang H, Yang G, Hong Z, Han D, et al. DI-3-n-butylphthalide prevents the disruption of blood-spinal cord barrier via inhibiting endoplasmic reticulum stress following spinal cord injury. Int J Biol Sci. 2017;13:1520-31.

50. Hua Y, Schallert T, Keep RF, Wu J, Hoff JT, Xi G. Behavioral tests after intracerebral hemorrhage in the rat. Stroke. 2002;33(10):2478-84.

51. He T, Zuo Y, Ai-Zakwani K, Luo J, Zhu H, Yan XX, et al. Subarachnoid hemorrhage enhances the expression of TDP-43 in the brain of experimental rats and human subjects. Exp Therap Med. 2018;16(4):3363-8.

52. Zhang J, Shi X, Hao N, Chen Z, Wei L, Tan L, et al. Simvastatin reduces neutrophils infiltration into brain parenchyma after intracerebral hemorrhage via regulating peripheral neutrophils apoptosis. Front Neurosci. 2018:12:977.

53. Zuo Y, Wang J, Liao F, Yan X, Li J, Huang L, et al. Inhibition of Heat Shock Protein 90 by 17-AAG reduces inflammation via P2X7R/NLRP3 inflammasome pathway and increases neurogenesis after Subarachnoid Hemorrhage in mice. Front Mol Neurosci. 2018;11:401.

54. Longa EZ, Weinstein PR, Carlson S, Cummins R. Reversible middle cerebral artery occlusion without craniectomy in rats. Stroke. 1989;20:84-91.

55. Vizio B, Biasi F, Scirelli T, Novarino A, Prati A, Ciuffreda L, et al. Pancreaticcarcinoma-cell-derived pro-angiogenic factors can induce endothelialcell differentiation of a subset of circulating CD34+ progenitors. J Trans Med. 2013;11:314

56. Sidney LE, Branch MJ, Dunphy SE, Dua HS, Hopkinson A. Concise review: evidence for CD34 as a common marker for diverse progenitors. Stem Cells. 2014;32:1380-9.

57. Kong X, Guan J, Ma W, Li Y, Xing B, Yang Y, et al. CD34 over-expression is associated with gliomas' higher WHO grade. Medicine (Baltimore). 2016;95:e2830.

58. Sarmadi S, Izadi-Mood N, Movarei F, Sefidbakht S, Sotoudeh K, Jahanzad E. Association of neo angiogenesis by CD34 expression and clinicopathologic features in squamous cell carcinoma of cervix. CTA Med Iran. 2017:55:282-9.

59. Ferrara N. VEGF: an update on biological and therapeutic aspects. Curr Opin Biotechnol. 2000;11:617-24.

60. Geiseler SJ, Morland C. The janus face of VEGF in stroke. Int J Mol Sci. 2018;19:E1362.

61. Maharaj AS, Saint-Geniez M, Maldonado AE, D'Amore PA. Vascular endothelial growth factor localization in the adult. Am J Pathol. 2006;168:639-48

62. Quan W, Zhang Z, Tian Q, Wen X, Yu P, Wang D, et al. A rat model of chronic subdural hematoma: insight into mechanisms of revascularization and inflammation. Brain Res. 2015;1625:84-96.

63. Mărgăritescu O, Pirici D, Mărgăritescu C. VEGF expression in human brain tissue after acute ischemic stroke. Rom J Morphol Embryol. 2011;52:1283-92.

64. Zan L, Zhang X, Xi Y, Wu H, Song Y, Teng G, et al. Src regulates angiogenic factors and vascular permeability after focal cerebral ischemia-reperfusion. Neuroscience. 2014;262:118-28.

65. Karamysheva AF. Mechanisms of angiogenesis. Biochemistry (Mosc). 2008;73:751-62.

66. Guan W, Somanath PR, Kozak A, Goc A, El-Remessy AB, Ergul A, et al. Vascular protection by angiotensin receptor antagonism involves differential VEGF expression in both hemispheres after experimental stroke. PLOS ONE. 2011;6:e24551.

67. Saharinen P, Bry M, Alitalo K. How do angiopoietins tie in with vascular endothelial growth factors? Curr Opin Hematol. 2010;17:198-205.

68. Jászai J, Schmidt MHH. Trends and challenges in tumor anti-angiogenic therapies. Cells. 2019;8:E1102.

69. Maishi N, Annan DA, Kikuchi H, Hida Y, Hida K. Tumor endothelial heterogeneity in cancer progression. Cancers (Basel). 2019;11:E1511.

70. Rosenberg GA, Mun-Bryce S, Wesley M, Kornfeld M. Collagenase-induced intracerebral hemorrhage in rats. Stroke. 1990;21:801-7.

\section{Publisher's Note}

Springer Nature remains neutral with regard to jurisdictional claims in published maps and institutional affiliations.

Ready to submit your research? Choose BMC and benefit from:

- fast, convenient online submission

- thorough peer review by experienced researchers in your field

- rapid publication on acceptance

- support for research data, including large and complex data types

- gold Open Access which fosters wider collaboration and increased citations

- maximum visibility for your research: over $100 \mathrm{M}$ website views per year

At BMC, research is always in progress.

Learn more biomedcentral.com/submissions 